\title{
Visual outcomes of surgical management in eyes with severely traumatized eyes presenting with no-light-perception vision
}

\author{
Mehul Shah*, Shreya Shah, Kashyap Patel and Pramod Upadhyay \\ Drashti Netralaya, Dahod, Gujarat, India
}

\begin{abstract}
Background: Severe ocular trauma that causes no light perception (NLP), typically carries a dismal prognosis, and implies no further therapeutic intervention. The present investigation attempts to identify a cohort of patients with ocular injury and verified NLP, who recovered vision of light perception (LP) or did even better as the result of vitreoretinal surgery performed following the open-globe injury.
\end{abstract}

Methods: The study is a retrospective review of the outcomes of surgeries performed at Drishti Netralaya, between 1 January 2005 and 31 December 2013 , on all cases of ocular injuries with accompanying NLP on presentation.

Results: A total of 4721 cases of ocular injuries were presented during the study period, of which 6.2\% (324) cases exhibited NLP on presentation. 84\% of the NLP group (275) were unwilling for surgery because of severe structural damage or extremely guarded prognosis. These patients were operated either for cosmetic reasons or to remedy the destruction. Only $9 \%$ (29) of this group underwent vision salvaging surgery. Among the eyes that underwent surgery, 8 (27\%) had improvement, with vision ranging from hand motion to finger counting near face. Without exception, patients who did not undergo vitreoretinal surgery either returned to NLP, or became phthisic within a year.

Conclusion: Patients with severe ocular injury and NLP occasionally recover light perception (LP) or better vision. Useful vision may be regained if surgical intervention is prompt - in such cases, spontaneous visual recovery occurs within the first week after injury.

\section{Introduction}

Trauma is a major cause of monocular blindness in the developed world. Very few studies have investigated this problem in rural areas [1], even though its aetiology is likely to differ between urban and rural areas [2-4]. The development of strategies for preventing such injuries requires identification of the causes. Prevention is imperative because the society as well as the victims themselves (particularly children, in whom ocular injury has a poor prognosis), bear a heavy burden that is potentially preventable ${ }^{3}$. Sufficient allocation of resources for the prevention of eye injuries would lighten this burden.

One consequence of ocular trauma is the formation of cataracts ${ }^{1}$. Methodologies have been devised for evaluating visual outcomes in eyes with trauma-induced cataracts and non-trauma cataracts [5], but in the former, damage to surrounding ocular tissues may compromise the visual gain after surgery, thereby resulting in a varied success rate between the two. Traumatic cataracts often have poor visual outcomes in children due to amblyopia and recurrent inflammation

The Birmingham Eye Trauma Terminology System (BETTS) provides standardized definitions of ocular trauma ${ }^{5}$, thus serving a twofold purpose: (i) facilitating comprehension of the determinants for predicting the outcomes, and (ii) enabling comparison of visual outcomes following traumatic cataract surgery. Research literature does contain reports on visual outcomes of traumatic cataracts $[6,7]$, but most of them study individual cases or a small sample size.

Severely traumatized eye result in vision with no perception of light, but reports on medical and surgical management of this condition indicate that vision can be rehabilitated up to perception of light stage or better [8].
The objective: of the present investigation was to study visual recovery in eyes with NO PL following management

\section{Patients and methods}

Approval for this study was obtained from the hospital administrators and research committee. Written consent was obtained from the participants. The study was based on a retrospective design. Criteria for enrollment of patients included: diagnosis of ocular trauma in either eye between January 2003 and December 2009; absence of any other serious bodily injuries, and willingness to give written consent at the time of enrollment. Data on the subjects' medical history was retrieved from the institution's medical records, using a specific pretested online form.

All records marked 'presenting vision no perception of light' were separated, and the patients' perception of light was checked in a dark room by two observers.

\section{Data collection}

A detailed history of the injury and treatment (including surgery),

Correspondence to: Mehul Shah, Drashti Netralaya, Chakalia Road, Dahod-389151, Gujarat, India, Tel: 00-91-2673-251100; Fax: 00-91-2673251100; E-mail: omtrust@rdiffmail.com

Key words: No light perception (NLP), ocular trauma, Birmingham Eye Trauma Terminology System (BETTS)

Received: November 02, 2016; Accepted: November 21, 2016; Published: November 24, 2016 
was elicited from each enrolled patient by using forms specially designed for this purpose. Data for both initial and follow-up reports were collected using the online Birmingham Eye Trauma Terminology System (BETTS) format, laid down by the International Society of Ocular Trauma, while information about the surgery was gathered using a specific pre-tested online form. Demographic details comprised patient characteristics, residence, and activity at the time of injury, cause of injury, and previous examinations and treatment modes. The elicited data was exported into a Microsoft Excel spreadsheet, and audited periodically to ensure complete data collection

\section{Categorisation of patients}

The trauma cases were divided into two groups, namely, open globe injury group and closed globe injury group:

Open globe injury group - this was further categorised into (i) laceration group, (with sub-categories of perforating injury, penetrating injury, and injury involving an intraocular foreign body), and (ii) rupture group.

Closed globe group -- this was further divided into lamellar laceration group and contusion group.

\section{Examination}

Standard procedures were followed for the examination of enrolled patients. The anterior segment was examined using a slit lamp. For a partially opaque lens, a posterior segment examination was performed with an indirect ophthalmoscope and a $+20 \mathrm{D}$ lens. When the optical medium was not clear, a B-scan was performed to evaluate the posterior segment.

\section{Treatment}

\section{Surgery}

The surgical technique was selected according to the location of affected tissues within the anterior to posterior segment range. Wound repair was done for open globe injuries, and further vitreoretinal surgeries performed to attain anatomical success. Closed globe injuries also were managed for anterior and posterior segment injuries. IOP control was achieved using medical and surgical management.

In patients undergoing corneal wound repair, the traumatic cataract was managed using a second procedure. Recurrent inflammation was more prominent in patients who had undergone previous surgery for trauma[8,9]. Haziness of ocular medium due to inflammation of the anterior vitreous was addressed with a capsulectomy and vitrectomy procedure performed via an anterior/pars plana route. Children below 2 years of age were subjected to both lensectomy and vitrectomy via the pars plana route. All children were treated by a qualified pediatric orthoptist for supportive amblyopia therapy, and by a pediatric ophthalmologist.

\section{Medication and follow-up procedure}

Patients with injuries sans infection were prescribed topical and systemic corticosteroids and cycloplegics, duration of medical treatment depending on the extent of inflammation in the anterior and posterior segments of the operated eye. The operated patients were re-examined after 24 hours, 3 days, and 1, 2, and 6 weeks, to enable refractive correction. Follow-up was scheduled for day 3, weekly for 6 weeks, monthly for 3 months, and thereafter every 3 months for 1 year.

Every follow-up examination included a visual acuity test according to age, using the AAO guidelines. The anterior segment was examined with a slit lamp, and the posterior segment was examined with an indirect ophthalmoscope.

\section{Data analysis}

The post-treatment visual outcome was predicted from the Ocular Trauma Score (OTS), by calculating the raw score based on the presenting vision and condition. This prediction was then statistically compared with the actual visual outcome. The Statistical Package for Social Sciences (SPSS ver. 22) was used to analyze the data. Descriptive statistics and cross-tabulation were used to compare the cause and effect of different variables.

\section{Results}

A total of 4721 patients were reviewed, of which 324 (6.9\%) patients were found to have no light perception on presentation. Median age was $35+/-21$, ranging from 1 to 84 years; 98 (30.2\%) patients of the total were paediatric patients. 324 patients were enrolled, of which $243(75 \%)$ male and $81(25 \%)$ were female (Table1). With respect to the socioeconomic status, $87 \%$ hailed from a poor socio economic background. Out of 29 vision salvaging procedures, 8 (27.6\%) regained vision > NO PL. Acceptable anatomic success could be achieved in all cases.

A comparative study was done based on type of injury as classified by BETTS, and no significant difference was found $(p=0.139)$ (Table 2). No surgical procedure was performed on 275 (84.9\%) cases; cosmetic and plastic surgery were performed on 20 (6.2\%) cases, and vision salvaging surgeries were performed on 29 (9\%) cases (Table 3).

Results from the group which underwent surgical treatment were compared with those from the untreated group, and it was found that surgical treatment contributed significantly to for visual outcome ( $p=$ 0.000) (Table 4).

Table 1. Age and gender distribution.

\begin{tabular}{|c|c|c|c|}
\hline & \multicolumn{2}{|c|}{ Gender } & \multirow[t]{2}{*}{ Total } \\
\hline & Female & Male & \\
\hline 0 to 10 & 24 & 41 & 65 \\
\hline 11 to 20 & 7 & 30 & 37 \\
\hline 21 to 30 & 5 & 37 & 42 \\
\hline 31 to 40 & 9 & 37 & 46 \\
\hline 41 to 50 & 13 & 24 & 37 \\
\hline 51 to 60 & 13 & 46 & 59 \\
\hline 61 to 70 & 10 & 23 & 33 \\
\hline 71 to 80 & 0 & 4 & 4 \\
\hline 81 to 90 & 0 & 1 & 1 \\
\hline Total & 81 & 243 & 324 \\
\hline
\end{tabular}

Table 2. Comparative study according to type of injury.

\begin{tabular}{|l|c|c|c|c|}
\hline \multirow{2}{*}{ Vision category } & \multicolumn{3}{|c|}{ Type of injury } & \multirow{2}{*}{ Total } \\
\cline { 2 - 5 } & Adnexa & Closed & Open & \\
\hline NOPL & 100 & 113 & 103 & 316 \\
\hline > NOPL & 0 & 4 & 4 & 8 \\
\hline Total & 100 & 117 & 107 & 324 \\
\hline
\end{tabular}

Table 3. Categories of surgical procedures.

\begin{tabular}{|l|c|c|}
\hline Surgical category & Frequency & Percentage (\%) \\
\hline Cosmetic & 20 & 6.2 \\
\hline Nil & 275 & 84.9 \\
\hline Vision salvaging & 29 & 9.0 \\
\hline Total & 324 & 100.0 \\
\hline
\end{tabular}


Table 4. Comparative study between surgical and non-surgical group.

\begin{tabular}{|l|c|c|c|}
\hline \multirow{2}{*}{ Vision category } & \multicolumn{2}{|c|}{ Surgery } & \multirow{2}{*}{ Total } \\
\cline { 2 - 3 } & No & Yes & \\
\hline NOPL & 287 & 29 & 316 \\
\hline$>$ NOPL & 3 & 5 & 8 \\
\hline Total & 290 & 34 & 324 \\
\hline
\end{tabular}

Table 5. Types of vision salvaging surgeries.

\begin{tabular}{|l|c|c|}
\hline Name of surgery & No & Percentage (\%) \\
\hline Glaucoma & 3 & 10.3 \\
\hline Traumatic cataract & 9 & 31.0 \\
\hline Vitrectomy & 11 & 37.9 \\
\hline Corneo scleral wound repair & 6 & 20.7 \\
\hline Total & 29 & 100 \\
\hline
\end{tabular}

Table 5 displays the variety of surgeries performed on the subjects of study. No significant difference was observed among the different tissues affected by injury. Similarly, the nature of activity during injury, and the object causing injury both did not significantly affect the results.

\section{Discussion}

4721 patients were reviewed, of which 324 (6.9\%) patients were found to have NLP or no light perception on presentation.

The timing of presentation is an important consideration, because in paediatric patients, the media opacity may be crucial for visiondeprivation amblyopia. Lens vitreous admixture when present, is a potent stimulator for further proliferative vitreoretinopathy, and moreover, can result in traction on the retina; hence primary extraction of the lens and vitreous is imperative in such patients. Late presenting injuries may have greater inflammation disc, and macular changes may further lead to difficulty in decision-making about perception [12].

Data from the present review suggests that presenting at 2-30 days after injury results in improved visual outcomes. ${ }^{12}$ Introduction of the Birmingham Eye Trauma Terminology (BETT) system has standardized documentation of ocular trauma. The international classification of ocular trauma, which was proposed almost 15 years ago, requires re-evaluation, and should be more robust in terms of predicting the outcome [8].

Visual outcomes of trauma in children have been reported, although most studies involved only small samples or were case studies [13]. Several reports on the management of NOPL cases mention that. some visual recovery is prevalent, but Haideri et al. [14] reported visual acuity of only $20 / 200$ in $33.6 \%$ cases. In the present study, patients regained post-operative perception to hand motion. Hen [15] reported visual recovery in NPL cases. Salehi-Had $\mathrm{H}$ et al. [16] reported cases with improvement following secondary vitreo retinal surgeries [16]. Feng $\mathrm{K}$ et al. [17] reported visual recovery in NPL cases, and found prognostic factors like ciliary body damage, closed funnel retinal detachment and choroidal damage. Ren et al. [18] reported vitrectomy in $6 \mathrm{No} \mathrm{Pl}$ cases using endoscopic vitrectomy, and also reported some visual gain.

Assessment of light perception is a subjective measure and not a foolproof test in the presence of severe media opacity secondary to dense vitreous hemorrhage, traumatic cataract, dense hyphema and corneal edema $[8,9]$. Assessment of light perception even with the bright light of an indirect ophthalmoscope can give false impression of NLP [10]. Light perception in case of severe ocular trauma seen in the paediatric age group, and may therefore be a confounding factor. Even in situations in which enucleation seems inevitable the ophthalmologist should discuss the possible options with the patient, before taking a final decision. Primary enucleation for severely traumatized eyes with NLP in view of risk of sympathetic ophthalmia, was a controversial approach. Sympathetic ophthalmia with potential for bilateral blindness is a relative indication for enucleation of an injured eye [19]. Most reported cases (65\%) occur between 2 weeks to 2 months after injury, and rarely occur during the first 2 weeks after trauma [19]. However, the actual rate of post-traumatic sympathetic ophthalmia is not clear, and reported rates vary from $0.28 \%$ to $1.9 \%[9,19]$. The use of modern immunosuppressive drugs has also improved treatment and control of sympathetic ophthalmia. As such, primary surgical repair should not be abandoned for the risk of sympathetic ophthalmia in eyes with NLP. Currently, most surgeons recommend globe salvaging procedure for eyes with severe trauma with no light perception vision at initial presentation.

Visual acuity can be profoundly impaired to the extent of no light perception (NLP) in presence of significant media opacity (e.g. corneal oedema, hyphema, cataract, and dense vitreous haemorrhage), retinal detachment, associated subretinal or subhyaloid haemorrhage, haemorrhagic choroidals and even psychological factors (e.g. hysteria) [19]. Ultrasonography is useful for assessment of posterior segment in the eyes with media opacity, and to differentiate between retinal detachment and vitreous haemorrhage, but it is sometimes difficult to differentiate a detached retina from blood clots in the vitreous cavity or membranes. ${ }^{19}$ Before deciding on enucleation in patients with NLP, reversible causes of vision loss should be excluded including psychological factors $[19,20]$.

Optic neuritis following trauma may cause dense central scotoma which may be falsely interpreted as a NPL case. Medical management with cortical steroids may lead to reduction in central scotoma, resulting in light perception. Traumatic optic neuropathy causing no perception in light, may be because of a direct optic nerve injury, or injury to vascular supply in the region [21].

\section{References}

1. Khatry SK, Lewis AE, Schein OD, Thapa MD, Pradhan EK, et al. (2004) The epidemiology of ocular trauma in rural Nepal. Br J Ophthalmol 88: 456-460. [Crossref]

2. Abraham DI, Vitale SI, West SI, Isseme I (1999) Epidemiology of eye injuries in rural Tanzania. Ophthalmic Epidemiol 6: 85-94. [Crossref]

3. Alfaro DV 3rd, Jablon EP, Rodriguez Fontal M, Villalba SJ, Morris RE (2005) Fishingrelated ocular trauma. Am J Ophthalmol 139: 488-492. [Crossref]

4. Shah M, Shah S, Khandekar R (2008) Ocular injuries and visual status before and after their management in the tribal areas of Western India-A historical cohort study. Grafes Arch Clin Exp Ophthalmol 246: 191-197.

5. Kuhn F, Morris R, Witherspoon CD, Mester V (2004) The Birmingham Eye Trauma Terminology system (BETT). J Fr Ophtalmol 27: 206-210. [Crossref]

6. Gradin D, Yorston D (2001) Intraocular lens implantation for traumatic cataract in children in East Africa. J Cataract Refract Surg 27: 2017-2025. [Crossref]

7. Morgan KS (1993) Cataract surgery and intraocular lens implantation in children. Curr Opin Ophthalmol 4: 54-60. [Crossref]

8. Agrawal R, Shah M, Mireskandari K, Yong GK (2013) Controversies in ocular trauma classification and management: review. Int Ophthalmol 33: 435-445. [Crossref]

9. Morris R, Kuhn F, Witherspoon CD (1999) Management of the opaque media eye with no light perception. In: Alfaro DV III, Liggett PE. Vitreoretinal Surgery of the Injured Eye. Philadelphia: Lippincott-Raven 113-124.

10. Striph GG, Halperin LS, Stevens JL, Chu FC (1988) Afferent pupillary defect caused by hyphema. Am J Ophthalmol 106: 352-353. [Crossref]

11. Abrams GW, Kington RW (1984) Falsely extinguished bright light flash 
electroretinogram. Its association with dense vitreous hemorrhage. Arch Ophthalmol 100: $1427-1429$.

12. Shah MA, Shah SM, Shah SB, Patel UA (2011) Effect of interval between time of injury and timing of intervention on final visual outcome in cases of traumatic cataract. Eur J Ophthalmol 21: 760-765. [Crossref]

13. Shah MA, Shah SM, Chaudhry AH, Pannu S (2015) Traumatic cataracts in children: Visual outcome. World J Ophthalmol 5.

14. Heidari E, Taheri N (2010) Surgical treatment of severely traumatized eyes with no light perception. Retina 30: 294-299. [Crossref]

15. Han YS, Kavoussi SC, Adelman RA (2015) Visual recovery following open globe injury with initial no light perception. Clin Ophthalmol 9: 1443-1448. [Crossref]

16. Salehi-Had H, Andreoli CM, Andreoli MT, Kloek CE, Mukai S (2009) Visual outcomes of vitreoretinal surgery in eyes with severe open-globe injury presenting with no-lightperception vision. Graefes Arch Clin Exp Ophthalmol 247: 477-483. [Crossref]
17. Feng K, Shen L, Pang X, Jiang Y, Nie H et al. (2011) Case-control study of risk factors for no light perception after open-globe injury: eye injury vitrectomy study. Retina 31 : 1988-1996. [Crossref]

18. Ren H, Jiang R, Xu G, Chang Q, Lyu J, et al. (2014) Evaluation of endoscopy assisted vitrectomy for the treatment of severe traumatic eyes with no light perception. Zhonghua Yan Ke Za Zhi 50: 194-196. [Crossref]

19. Makley TA Jr, Azar A (1978) Sympathetic ophthalmia. A long-term follow-up. Arch Ophthalmol 96: 257-262. [Crossref]

20. Rabinowitz R, Yagev R, Shoham A, Lifshitz T (2004) Comparison between clinical and ultrasound findings in patients with vitreous hemorrhage. Eye (Lond) 18: 253-256. [Crossref]

21. Tabatabaei SA, Soleimani M, Alizadeh M, Movasat M, Mansoori MR, et al. (2011) Predictive value of visual evoked potentials, relative afferent pupillary defect, and orbital fractures in patients with traumatic optic neuropathy. Clin Ophthalmol 5: 10211026. [Crossref]

Copyright: (C2016 Shah M. This is an open-access article distributed under the terms of the Creative Commons Attribution License, which permits unrestricted use, distribution, and reproduction in any medium, provided the original author and source are credited. 